\title{
A Meso Level FE Model for the Impact Bullet - Yarn
}

\author{
CATALIN PIRVU¹, ANDREA ELENA MUSTEATA², GEORGE GHIOCEL 0J OC², SIMONA SANDU³, LORENA DELEANU2* \\ ${ }^{1}$ National Institute of Aerospace Research Elie Carafoli (INCAS), 220 luliu Maniu Blvd., 061099, Bucharest, Romania \\ 2 Dunarea de Jos University, Faculty of Engineering, 47 Domneasca, 800008, Galati, Romania \\ ${ }^{3}$ Scientific Research Center for CBRN Defense and Ecology, 225 OItenitei, 041327, Bucharest, Romania
}

\begin{abstract}
This paper presents a study based on simulating the impact between a yarn (or a single fiber with greater dimensions) and a bullet, the impact velocity being $400 \mathrm{~m} / \mathrm{s}$. The characteristics of the involved materials are taken from literature. The yarn is considered isotrope, but the values of the characteristics are close to those of aramid fibers and cooper and lead alloys used for manufacturing the bullets. Analysing the yarn failure caused by a bullet, this FE model allows for identfying the stages in the failure process. First, the yarn is pushed by the bullet and the local elongation of the yarn is tacking place. The yarn rupture occurs in the "strangled" zones, caused by the stretch of the yarn directly supporting the impact. The breaking of the yarn in the thinned zone (more pronounced asymmetric breaking) and it is visible that the yarn elastic recoil starts next the bullet. The friction between the yarn and the bullet is only on the conical surface of the bullet in the tapered zone of the bullet. The yarn is detaching from the bullet (the contactzones between the bullet and the yarn in polymeric matrix become smaller, justifying a neglectable influence of the thermal effect). The yarn has no more contact with the bullet. This step is in the favor of the assumption that, in the actual multi-yarn impact, the other layers of yarns maintain the bullet and the first yarns in contact and this is why bunch of fibers (fragments of the failed yarns) are pressed against the bullet and remain on it. The simulation results were qualitatively validated by SEM investigations of fiber failure under the same conditions as the model.
\end{abstract}

Keywords: FE model, ballistic impact, polymeric yarn

Components of mechanical systems are made of different materials and their mechanical answer under load is

related to the characteristic cohesive forces. Although progress has been done in the research field for expressing the mechanical behavior of a material under complex loading, including high speed impact, the obtained relations are complicated and difficult to introduce in analytical models. New constitutive models for materials under load are reported in the literature [1-6], both for pseudo-static cases and dynamic ones. The J ohnson-Cook model $[7,8]$, Gruneisen [8] and similar ones presented in [9], accept the hypothesis of continuum medium and include experimental results and observations from measurable macroscopic processes: elasticitaty; plasticity; viscosity; creep, hardening, effects due to high strain rate and temperature etc. A semi-empirical or physical model takes into account the atom arrangement and microscopic phenomena and even the atom dislocations in the crystalline lattice [11-13].

Some analytical models are designed by coupling virtual mechanical elements with properties of interest (a spring for linear elasticity, a cylinder working with a viscous fluid for damping and a friction element for plasticity). The complex mechanical behavior could be obtained by combining in line, in parallel or in complex links, the abovementioned elements. The actual materials have behaviors betw een two extremes: the perfect rigid body (that moves without changing its shape and the ideal fluid (that moves under very low external load). The use of values characterizing the mechanical properties under cvasistatic conditions could give some inconsistency between numerical and experimental results [14, 15]. But for particular models, acceptable results may be obtained by simplifying the yarn to an elastic or elasto-plastic material.

Cormos et al. [16] obtained some differences between experimental and simulation data because of complex

\footnotetext{
* email: lorena.deleanu@ugal.ro, Phone: (+40)743105835
}

shape (a multilayered honeycomb composite) and because the material was considered homogeneous. This assumption was made because the difficulty of considering the natural mechanical properties of a material.

Lim et al. [17] and Tabiei and Ivanov [14] used a threeelement spring-dashpot model for describing the viscoelastic behavior of the Twaron fibers. Viscoelasticity characterises all the materials, butit significantly influences the behavior of polymers at room temperature. The creep and the relaxion are results of the viscoelastic nature of materials. In order to simulate the impact on these materials, many researchers have considered neglectable the effects on long terms on the mechanical properties and, thus, the material behavior could be described by a simple combination of a Maxwell element without the damping one and a Kelvin-Voigt element.

Wang and Xia [18] designed a model with a bimodal statistical Weibull distribution for describing the dependence between the strain rate and the stress values for the bunch of yarns made of Kevlar 49, for a strain rate range characterising the ballistic impact $\left(10^{-4} \mathrm{~s}^{-1} \ldots 10^{3} \mathrm{~s}^{-1}\right)$ and Wagner reported a statistical approach of the mechanical behavior of the aramid yarn [19] .

Mishnaevsky [20,21] proposed investigating and modelling of composites on three levels: micro, meso and macro and Botan et al. [22] analyzed the influence of the bonding between matrix and a spherical bead (as a microcell of a composite) on the stress distribution.

When modelling the impact on these fibers or their fabrics, it is adequate to take into account their sensitivity of properties to the strain rate, such as the elastic modulus and ultimate strength.

There are models of aramid fibers at molecular (micro) $[23,24]$, but they are difficult to be used in a meso or especially macro models $[25,26]$. Roylance [27] pointed out that the visco-elastic behavior of aramid fibres produces a transversal propagating wave of the shock that is slower and depending on the strain rate. 
Shim [28] proposed a simple model based on KleinVoight model: a spring in line with a sub-system made of a parallel link between another spring and a dash-pot (fig. 1, table 1), for describing the behavior of a Twaron aramid yarn, but only for small strains. Under tensile loading, the strain of aramid fiber is composed by the elongation of the molecular chains and the displacement of the molecular chains among them. The constants in table 1 are introduced with the help of the material properties $\left(E_{1}, E_{2}\right.$ the elastic modulus along the main axes and $\eta$ a viscosity constant), following the relations:

$$
E_{2}=\frac{k_{1}^{2}}{k_{2}}+k_{2}, \quad E_{1}=\frac{k_{1} k_{2}}{k_{1}}+k_{2}, \quad \eta=\frac{k_{1}^{2} \mu_{2}}{\left(k_{1}+k_{2}\right)^{2}}+k_{2},
$$

The difference between the parameters $k_{2}$ and $\eta$ is quite small for the fibers CT709 and CT716, except for $k_{1}$.

The fibers used for ballistic protection are also viscoelastic materials. Their constitutive models have to take into account of their sensitivity to strain rate. Properties like elastic modulus are dynamically dependent on the strain and strain rate.

Lim, Shim and Foo [29] gave curves stress-strain curves at different strain rates for yarns Twaron CT716, reporting a tensile limit of $1100 \ldots 1200 \mathrm{MPa}$ at strains of approx. $4.2 \ldots . .25 \%$, for strain rates of $238 \ldots . .268 \mathrm{~s}^{-1}$, but lower values $(950 \ldots 1100 \mathrm{MPa})$ for higher strain rates $\left(405 \ldots . .495 \mathrm{~s}^{-1}\right)$.

Gogineni [30] assumed that the rupture of the Twaron fibers is controlled by the maximum stress, hypothesis that could be applied to high speed impacts. For less sophisticated models, the mechanical properties (Poisson ratio, elastic modulus etc.) are assumed to be constant in time. The actual behavior is dependent with time, here including the dependence on strain rate as the variation of strain in time. If using static values during analysis of a woven or unidirectional fabric, some inconsistencies could be obtained between the numerical and experimental results. However, acceptable results are obtained by simplifying the behavior of fabrics as elastic membrane [31].
In 1958, Smith [12] proposed o theory that states the relation for the transversal wave in a yarn

$$
c=\sqrt{\frac{E}{\rho}}
$$

where $c$ is the velocity of the propagating transversal wave, $E$ - elasticity modulus de and $\rho$ - yarn density.

The constitutive model introduced by ohnson and Cook in 1983 [7] takes into account the influence of high strains, high strain rates and temperature and it is adequate for numerical analysis as it uses variables easy to be introduced in codes $[8,10,32,33]$. Data necessary for the constants could be obtained from tensile or torsion tests, for different temperatures. The model calculates the von Mises stress for yield as a function of the equivalent plastic strain, strain rate and the temperature calculated as softening factor.

Peroni [34] obtained stress-strain curves for different strain rates for a Cu-Sn alloy and a Pb-Sb alloy, for tensile and compression tests and the analytical expression of this dependence was given based on the principle of volume conservation under plastic deformation. The results pointed out the influence of the strain rate on the positioning of the stress-strain curves, but not on their shapes. When increasing the strain rate from $10^{-2}$ to $3.5 \times 10^{3}$, the actual value of the tensile stress was 2.5 times greater for the Sn$\mathrm{Pb}$ alloy and 520/330 times greater for the Cu-Sn alloy, at plastic strain value of 0.30 .

The purpose of this paper is to propose a model of a yarn that could behave similar to actual ones in order to use it in future work for restraining the ballistic tests, those being expensive and time consuming.

\section{Numerical simulation \\ Model for yarn}

The model of the yarn takes into account the properties of the aramid fiber, as given in literature, but at a meso level. It has to be mentioned that a yarn could have a high number of fibers. For instance, ballistically tested fabrics in

Table 1

THE CONSTANTS CHARACTERIZING THE STANDARD LINEAR MODEL FOR THE YARN OF ARAMID FIBERS

\begin{tabular}{|c|l|c|c|c|c|}
\hline Material & \multicolumn{1}{|c|}{ Authors } & $k_{I}(\mathrm{~Pa})$ & $k_{2}(\mathrm{~Pa})$ & $\eta(\mathrm{Pa} \cdot \mathrm{s})$ & \\
\hline \multirow{2}{*}{ CT716 } & $\begin{array}{l}\text { Shim V.P.W., Lim C.T. and Ng } \\
\text { Y.H. (2001) [27] }\end{array}$ & $1.07 \times 10^{11}$ & $2.65 \times 10^{9}$ & $4.57 \times 10^{6}$ & \\
\cline { 2 - 5 } & $\begin{array}{l}\text { Lim C.T., Shim V.P.W. and Foo } \\
\text { K.J. (2001) [28] }\end{array}$ & $1.57 \times 10^{10}$ & $2.75 \times 10^{9}$ & $2.90 \times 10^{6}$ \\
\hline CT709 & $\begin{array}{l}\text { David C.T., Shim V.P.W, Ng Y.H. } \\
\text { (2003) (quoted in [29]) }\end{array}$ & $6.8 \times 10^{10}$ & $2.8 \times 10^{9}$ & $3 \times 10^{6}$ & $\begin{array}{c}\text { Fig. 1. The model of the } \\
\text { standard linear solid } \\
(\mathrm{GM}(\mathrm{n}=1))\end{array}$ \\
\hline
\end{tabular}

Table 2

MATERIAL CONSTANTS FOR THE MODEL

\begin{tabular}{|c|c|c|c|c|c|c|c|}
\hline Material & $\begin{array}{c}\text { Density } \\
{\left[\mathrm{kg} / \mathrm{m}^{3}\right]}\end{array}$ & $\begin{array}{c}\text { Young } \\
\text { modulus } \\
{[\mathrm{MPa}]}\end{array}$ & $\begin{array}{c}\text { Poisson } \\
\text { ratio }\end{array}$ & $\begin{array}{c}\text { Bulk } \\
\text { modulus } \\
{[\mathrm{MPa}]}\end{array}$ & $\begin{array}{c}\text { Shear } \\
\text { modulus, } \\
{[\mathrm{MPa}]}\end{array}$ & $\begin{array}{c}\text { Yield limit } \\
{[\mathrm{MPa}]}\end{array}$ & $\begin{array}{c}\text { Tangent } \\
\text { modulus } \\
{[\mathrm{MPa}]}\end{array}$ \\
\hline Yam & $1.44 \times 10^{5}$ & 65000 & 0.35 & 72222 & 24074 & 630 & 1900 \\
\hline Copper alloy & $8.9 \times 10^{3}$ & $1.1 \times 10^{5}$ & 0.34 & $1.14 \times 10^{11}$ & 46400 & 280 & $1.15 \times 10^{9}$ \\
\hline Lead alloy & $11.34 \times 10^{5}$ & $1.6 \times 10^{4}$ & 0.3 & $4.44 \times 10^{10}$ & 8600 & 30 & $1.1 \times 10^{5}$ \\
\hline $\begin{array}{c}\text { Polymeric } \\
\text { matrix (PE) }\end{array}$ & $0.95 \times 10^{5}$ & & & & 117 & & \\
\hline
\end{tabular}

Table 3

MATERIAL CONSTANT IN SHOCK EOS LINEAR (SIMILAR TO $[40,41]$ )

\begin{tabular}{|l|c|c|c|c|}
\hline \multicolumn{1}{|c|}{ Material } & Gruneisen coefficient & $\begin{array}{c}\text { Cl } \\
{[\mathrm{mm} / \mathrm{s}]}\end{array}$ & Sl & $\begin{array}{c}\text { Quadratic parameter, } \\
{[\mathrm{mm} / \mathrm{s}]}\end{array}$ \\
\hline Polymeric matrix (PE) & 1.64 & $2.901 \times 10^{\circ}$ & 1.481 & 0 \\
\hline Lead & 2.64 & $2.006 \times 10^{\circ}$ & 1.429 & 0 \\
\hline Copper alloy & 2 & $3.958 \times 10^{\circ}$ & 1.497 & 0 \\
\hline
\end{tabular}


[35] have yarns composed of 1000 fibers. Even if a yarn has several hundreds of fibers, this model could be considered at meso level, as the yarn is associated to a single body having the properties close to those given in literature for the bunch of fibers. Thus, in this model the interyarn friction is not present and the yarn is considered isotropic, this being a hypothesis that is not characteristic to the aramid yarn thathas a strongly anisotropic character.

The characteristics of the materials, as introduced in the simulation, are presented in table 2 to table 5 . They were selected based on literature [36-39].

Other properties taken into account are:

- polymeric matrix $(P E)$ : maximum tensile stress 35 $\mathrm{MPa}$, maximum shear stress $17 \mathrm{MPa}$;

- yarn: failure criterion: maximum equivalent plastic strain: 0.1;

- lead alloy: constitutive model based on Steinberg Guinan strength;

- copper alloy: constitutive model: multilinear isotropic hardening.

\begin{tabular}{|c|c|}
\hline $\begin{array}{c}\text { Stress } \\
{[\mathbf{M P a}]}\end{array}$ & $\begin{array}{c}\text { Plastic strain } \\
{[\mathbf{m m} / \mathbf{m m}]}\end{array}$ \\
\hline 120 & 0 \\
\hline 450 & 0.3 \\
\hline 450 & $1 \times 10^{20}$ \\
\hline
\end{tabular}

Table 4

MODEL FOR THE COPPER ALLOY THE JACKET IS MADE OF

Another hypothesis: the model is isothermal. In the available literature, many models are designed as isothermal systems, at least for impact velocities close to that taking into account in this model (till $400 \mathrm{~m} / \mathrm{s}$ ) as the energy transformed into heat during the impact is not significant for modifying the fibers behavior. Other greater impact velocities need experiments with thermal field monitoring in order to verify if thermal energy is significant in the impact process [42-44],

This model considers the yarn made of two bodies: the yarn and its coating of polyethylene. Actually, the yarn is formed by hundreds or even thousands of fibers, but as one may notice in figure 3 , this model of the yarn is deformed and broken in the similar way as one fiber is.

For this model, the yarn is included in a polymeric matrix (fig. 2) (for instance, in some aramid fabrics, woven or unidirectional, the polyethylene is used as a thin foil to protected it, butalso to keep them together [45]. Literature gave simulation of woven fabrics under impact [46]. For this type of flexible packs for ballistic protection, thermoplastic polymers are used, but for other applications (like helmets) [47], the matrix is rigid [48-52].

For this model, the yarn material is solved with the constitutive model shock EOS linear [53]. The bullet is considered to be made of two materials, the jacket made of a copper alloy and the core made of lead alloy.
The code autoDyn used the explicit Dynamic solver.

The state equation was EOS shock $[53,54]$ the material being bilinear with hardening, characterized by a yield strength and a tangential modulus. The failure criterion was considered the maximum equivalent plastic strain, thus, the failure occurs when this value is reached.

The yarn was defined with a polymeric matrix around it, the hole assembly having here a parallellipipedic shape. The matrix is a body with different properties and the interface yarn - matrix was defined node on node and perfectly bonded. Thus, if the failure limit of the matrix is reached, the node is failing, too.

The body erosion is controlled by the program and imposed by the same factor as for the other bodies in the model [54], based on the geometrical deformation limit, each characterising a material.

For this type of impact and after studying literature [3, 56-60], the simulation was run for a time interval of $10^{-4} \mathrm{~s}$ (meaning a distance of $40 \mathrm{~mm}$ for the bullet with the imposed velocity of $400 \mathrm{~m} / \mathrm{s}$ without heating the target the yarn).

The model has a symmetry plan in the middle of the yarn and bullet (fig. 2) and the simulation was done with this half-system as all the involved bodies have this geometrical characteristic. Thus, the running time is considerable reduced.

\section{Conditions}

Contact conditions are: the contact between the bullet core and its jacket and also the contact between the polymeric matrix and the yarn are considered perfect bonded and the contact between the polymeric matrix with the yarn within it and the bullet is a friction contact, characterized by a constant friction coefficient of 0.3 .

Boundary conditions. The yarn had fixed ends, that is the nodes on the lateral end surfaces of the yarn has no movement and no rotation.

Initial conditions. The bullet velocityjustbefore reaching the yarn surface is $400 \mathrm{~m} / \mathrm{s}$, characteristic for $9 \mathrm{~mm} \mathrm{FMJ}$ bullet for different fire arms, including gun barrel used in [35].

The mesh. For models with bodies with very different levels of dimensions, the mesh presents some issues. The yarn is very long as compared to its cross section dimensions. Also, the bullet is formed of two bodies: the core has all three dimensions (along axes) of the same order, but the jacket is obviously thinner. Both the bullet and the yarn have locally finer mesh with the help of a prefferential mesh generated with an influence sphere with a radius of $2 \mathrm{~mm}$ for the yarn and $4 \mathrm{~mm}$ for the bullet top, in the central contact zone. The yarn mesh has the minimum element size of $0.01 \mathrm{~mm}$ and the top bullet zone is characterized with a minimum element size of $0.04 \mathrm{~mm}$.

\section{Table 5}

MODEL FOR THE LEAD ALLOY THE CORE IS MADE OF

\begin{tabular}{|c|c|l|l|l|l|l|c|}
\hline $\begin{array}{c}\text { Initial } \\
\text { yield } \\
\text { stress, } \mathrm{Y}, \\
{[\mathrm{MPa}]}\end{array}$ & $\begin{array}{c}\text { Maximum } \\
\text { yield stress, } \\
\text { Ymax }[\mathrm{MPa}]\end{array}$ & $\begin{array}{c}\text { Hardening } \\
\text { constant } \mathrm{B}\end{array}$ & $\begin{array}{c}\text { Hardening } \\
\text { exponent } \mathrm{n}\end{array}$ & $\begin{array}{c}\text { Derivative } \\
\mathrm{dG} / \mathrm{dP} \mathrm{G} \mathrm{P}\end{array}$ & $\begin{array}{c}\text { Derivative } \\
\mathrm{dG} / \mathrm{dT} \mathrm{G} T \\
{\left[\mathrm{MPa} /{ }^{\circ} \mathrm{C}\right]}\end{array}$ & $\begin{array}{c}\text { Derivative } \\
\mathrm{dY} / \mathrm{dP} \mathrm{Y} P\end{array}$ & $\begin{array}{c}\text { Melting } \\
\text { temperature, } \\
\text { Tmelt }\left[{ }^{\circ} \mathrm{C}\right]\end{array}$ \\
\hline 8 & 100 & 110 & 0.52 & 1 & -9.976 & $9.3 \times 10^{-4}$ & 486.85 \\
\hline
\end{tabular}

\begin{tabular}{|l|c|c|}
\hline Body & Number of nodes & Number of elements \\
\hline Jacket & 50946 & 283126 \\
\hline Core & 17793 & 96811 \\
\hline Bullet (jacket and core) & 68739 & 379937 \\
\hline Yarn & 105276 & 56550 \\
\hline Matrix & 251304 & 222807 \\
\hline Assembly yam-matrix & 356580 & 279357 \\
\hline
\end{tabular}

Table 6

MODEL OF BALLISTIC IMPACT BETWEEN BULLET AND YARN IN A POLYMERIC MATRIX (HERE PE) 


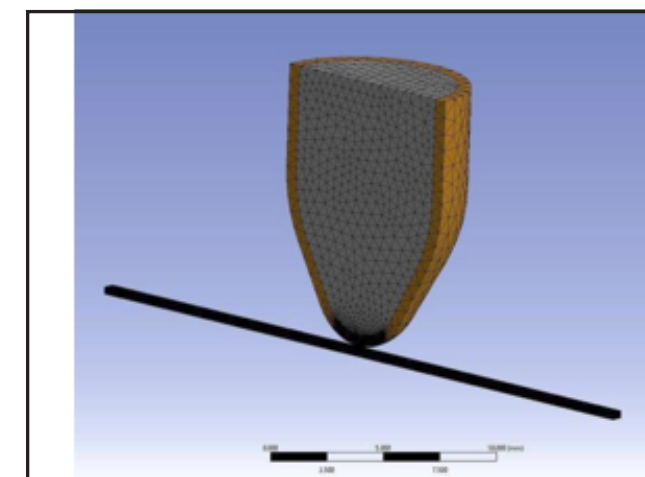

a) The model of the ballistic impact between a bullet and a yarn in a polymeric matrix

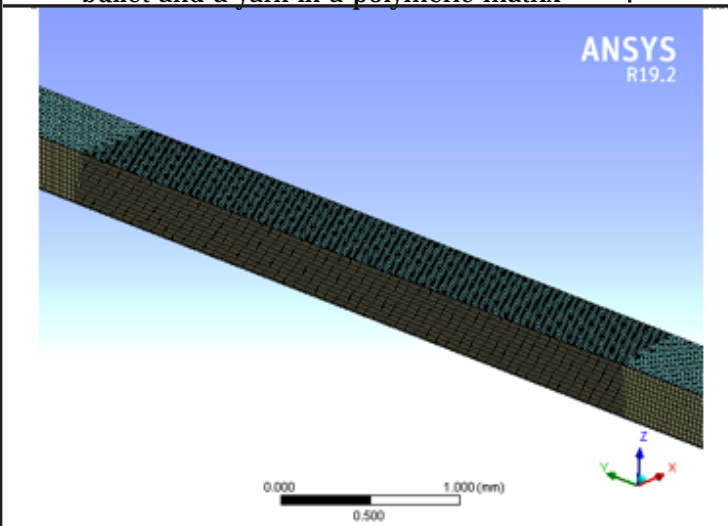

c) Detail of the mesh for the yarn in the central zone (the contact zone)

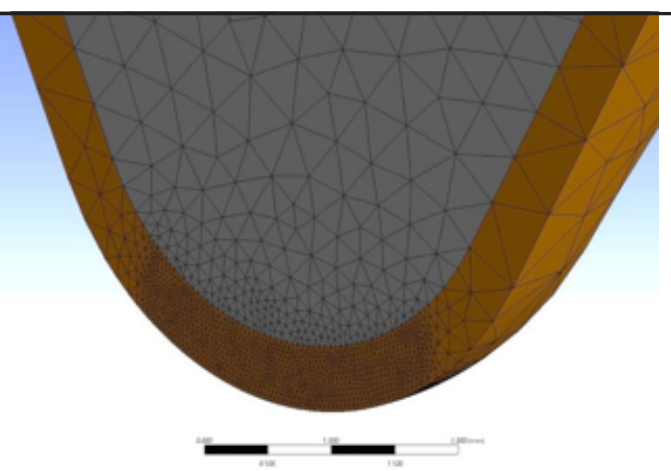

b) Detail of the mesh for the bullet top

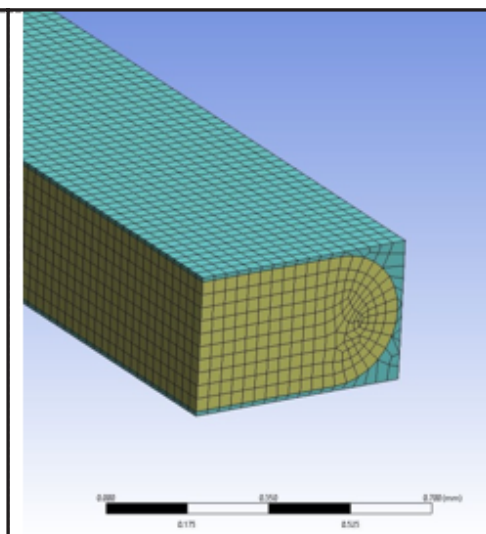

d) The mesh for the yarn in a polymeric matrix
Fig. 2 The mesh for the modeled system bullet + yarn in a PE matrix
Table 6 gives the number of nodes and elements for each body involved in this model.

The mesh sensitivity depends on the element size that should be as smaller as possible and a finer mesh could be requested on the bullet top. If these requests are fulfilled, the bullet behavior becomes more realistic (fig. 2b). Figure 2 presents the mesh as it was designed for this simulation of the impact between a bullet and a yarn in a polymeric matrix (the model was reduced to half the system because of symmetry reason and computer resources). It is preferable to have a superposition of the nodes of the yarn and those of the matrix, especially for zones that are expected to change shape or break and, thus, the element side of the matrix should be the same with that of the yarn.

Other authors have proposed lens shape for the yarn, as for instance, Gogineni [30] who analyzed the influence of the friction coefficient among yarns on the absorbed energy of the woven fabrics, on FEM models. Due to friction, the amount of energy absorbed by the fabric is increased. The friction is present when the bullet moves against the first yarns in contact but, also, there is friction between yarns that reduce the slipping among yarns.

\section{Results and discussions}

From this simulation, images in figure 3 were extracted at time steps of $1 \times 10^{-6} \mathrm{~s}$ and the authors could assign several stages in the yarn failure: deformation, elongation and thinning till braking (fig. $3 a$ and b), rupture (fig. 3c), bending of the yarn due to very fast advance of the bullet (fig. 3d, e and f) and the yarn recoil with destressing process (fig. 4).

a) On the free surface of the yarn, opposed to that in contact with the projectile, there are one or two zones with maximum value of von Mises stress and on the contact there are initiated smaller spots with high value of the stress $(800 \ldots 850 \mathrm{MPa})$, the yarn is not stressed yet in the zone far from the contact, b) After only $t=1 \times 10^{-6} \mathrm{~s}$, the stress field is dramatically changed: the longitudinal sections of the yarn has high stress concentrations near the direct contact bullet-yarn; also, the matrix is obviously broken near the contact; Sockalingham [38] also obtained a stress field that is modified in time in the cross section of a fiber, but for a 2D model impacted by an isotropic cylinder (made of one material, the actual projectile being conical with rounded tip, as it is in this simulation) and the fiber is model as an orthotropic material, but the failure criterion is set for the maximum principal stress. Also fiber has a circle shape but a much larger dimension as compared to an actual fiber or even an equivalent yarn. These authors also pointed out stress concentrators due to the bending of the fiber.

c) at $\mathrm{t}=3 \times 10^{-6} \mathrm{~s}$, the yarn is completely broken, the central fragment is isolated from the yarn and remain on the deformed tip of the projectile (a detail is offered in fig. $3 c)$. There are two zones of maximum stress on each part of the vertical axes of symmetry of the model. In this zone it is possible to have second breakages of the yarn (SEM photos in fig. 9d reveal longer detached fragments of the fibers).

d), e) and f) values of von Mises stress due to bending of the yarn remain high ( $823 \mathrm{MPa}$ in fig. 3d, $822 \mathrm{MPa}$ in fig. 3e and $f$ ) and the this zone of maximum stress migrates from near the contact to outside the contact.

The rupture of the yarn takes place after a section reduction, initially in two zones lateral to the bullet top zone (fig. $3 \mathrm{~b}$ and a detail in fig. 4). In the actual rupture of a fibre, there were noticed even twisted regions of the yarn as one may see in figure 11a and $c$ and their details (fig. 11b and d). The SEM images obtained for broken ends of the yarn fragments remained on a $9 \mathrm{~mm}$ bullet were get after arresting bullets in packs of 12 layers of LFT SBplus. For this simulation, the rupture of the yarn took place very quickly, between the moments $3.5 \times 10^{-5} \mathrm{~s}$ and $4.0 .10^{-5} \mathrm{~s}$ (It could be appreciated that the rupture process lasts around $1.10^{-6} . .5 \times 10^{-6} \mathrm{~s}$ ). 


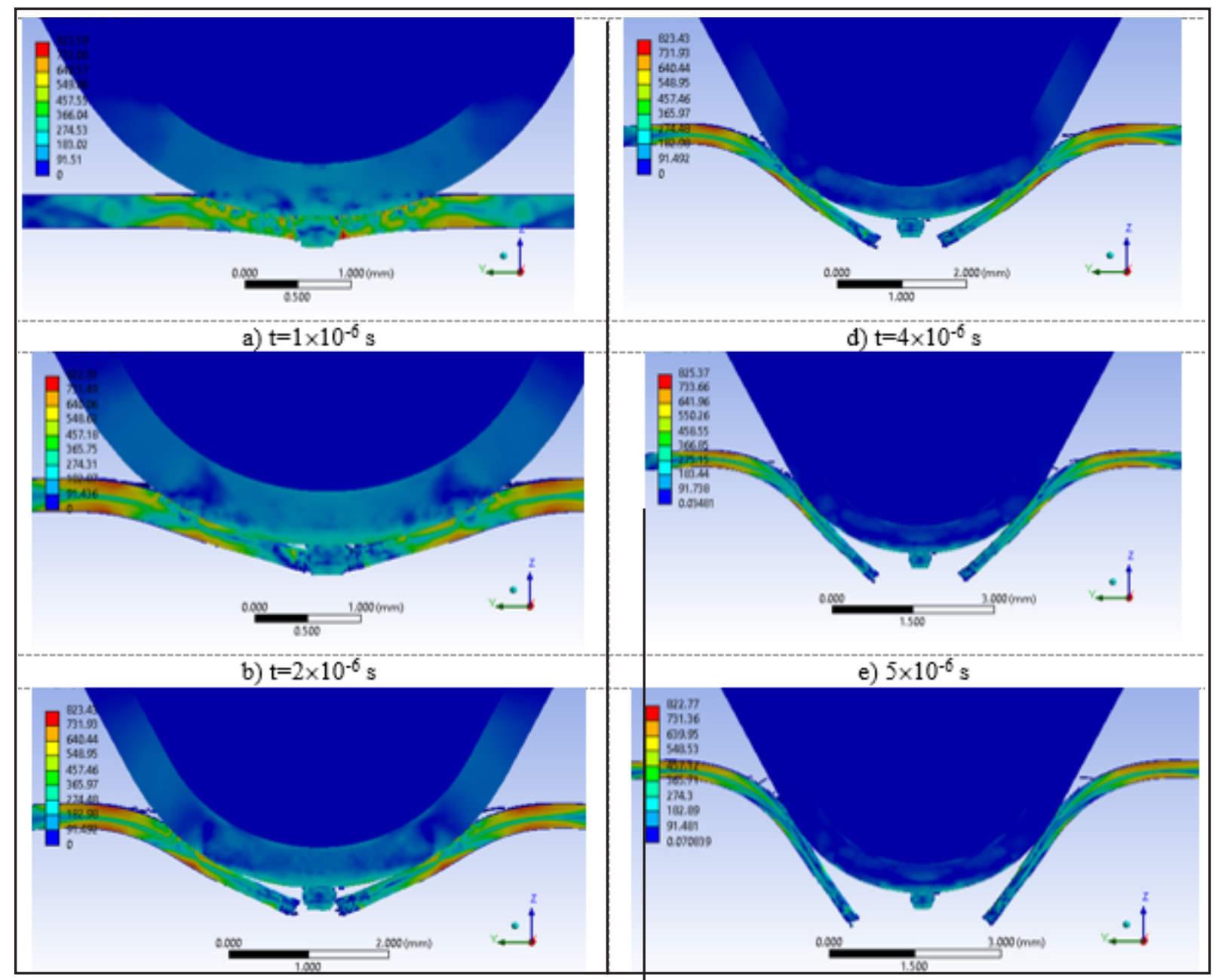

Fig. 3 The yarn behavior during the first moments of the impact (von Mises stress distribution, in $\mathrm{MPa}$ )

Figures 4 and 5 are taken at $t=1 \times 10^{-6} \mathrm{~s}$. Figure 4 points out a strong deformation for the yarn and the initiation of two stress concentrations on the opposite side of the contact. The bullet top is visible flattened, but in this model the jacked is oversized as thickness. The von Mises stress distribution is high in the central zone of the yarn, on its opposite side to the direct contact and very probably the first rupture is initiated without completely cut the yarn section. In the next moment ( $t=2 \times 10^{-6} \mathrm{~s}$, fig. 3b), this zone of maximum stress is dislodged from the model axes and the rupture is more visible in two zones, one in the left side, the other in the right side of the contact. Figure $5 a$ points out high values of von Mises stresses on the back face of the yarn, indicating zones with high probability of prakage (red color). Figure $5 \mathrm{~b}$ presents the top of the bullet, evidencing high values of stress.

The advance of the bullet is so quick that it engages the yarn to thin (fig. $3 a$ and $b$ ). As the yarn rupture is sudden and violent, the yarn movement may be characterized as a whipping action and the rebond is taking place after the passing of the bullet through the yarn. Thus, the response of the yarn material is typically elasto-viscous, taking into account the constitutive model for the yarn material.

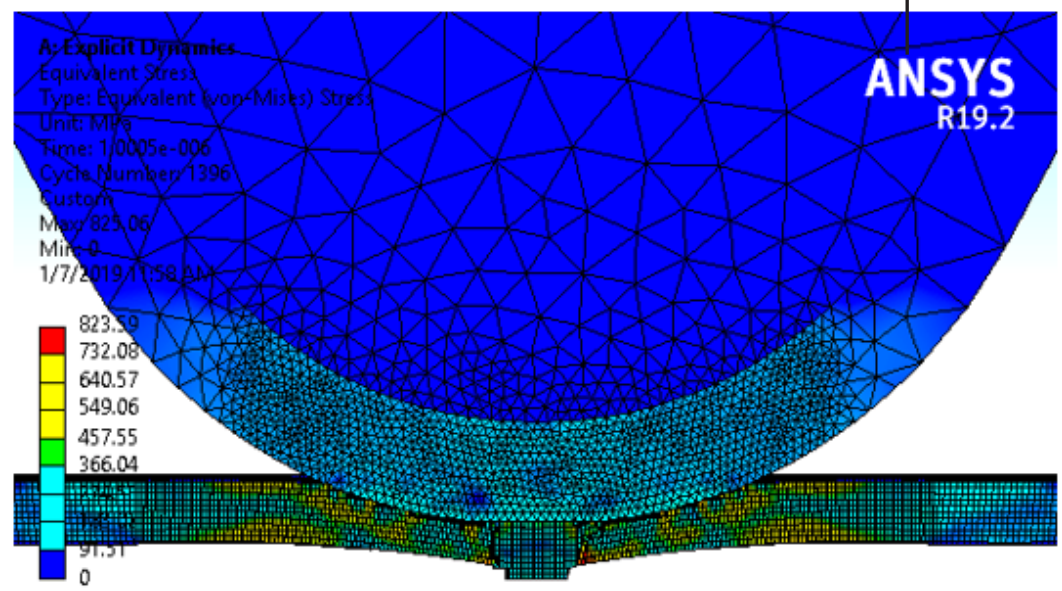

0.000

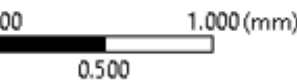

Fig. 4. Detail of the tip of the bullet at $t=1 \times 10^{-6} \mathrm{~s}$ (von Mises stress distribution, in $\mathrm{MPa}$ ) 


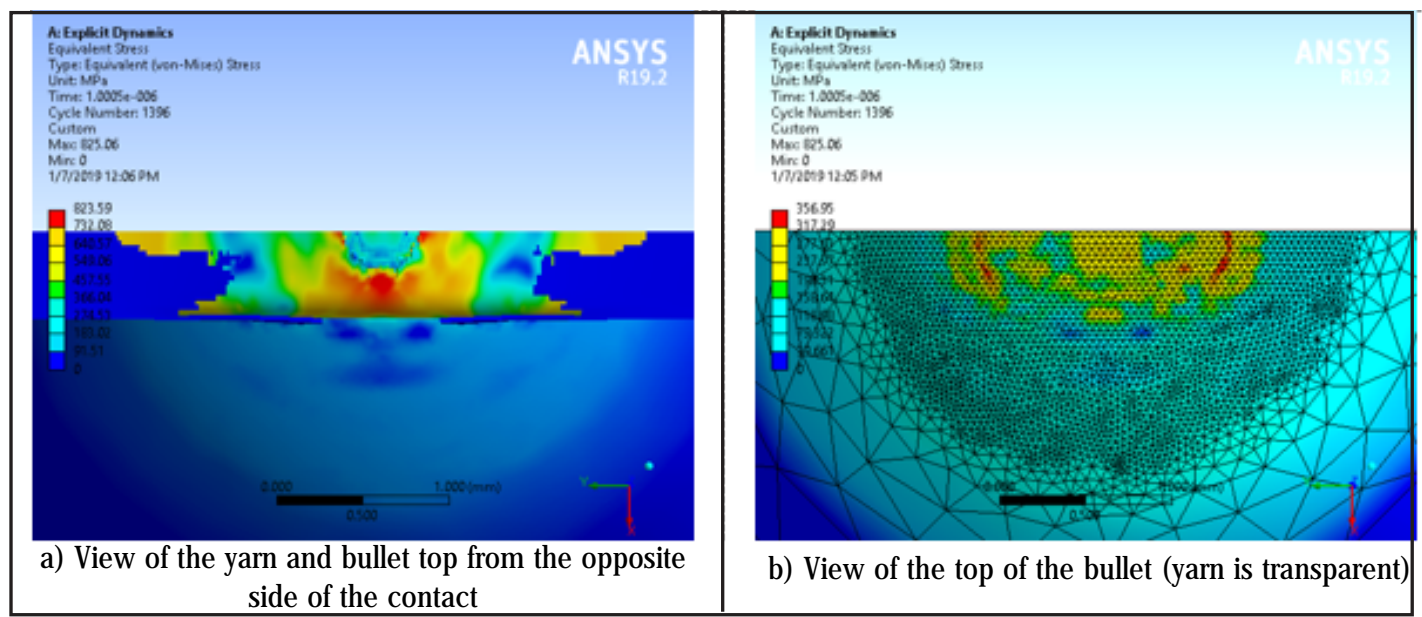

Fig. 5 Views from the opposite direction of the bullet velocity (von Mises stress distribution, in MPa)

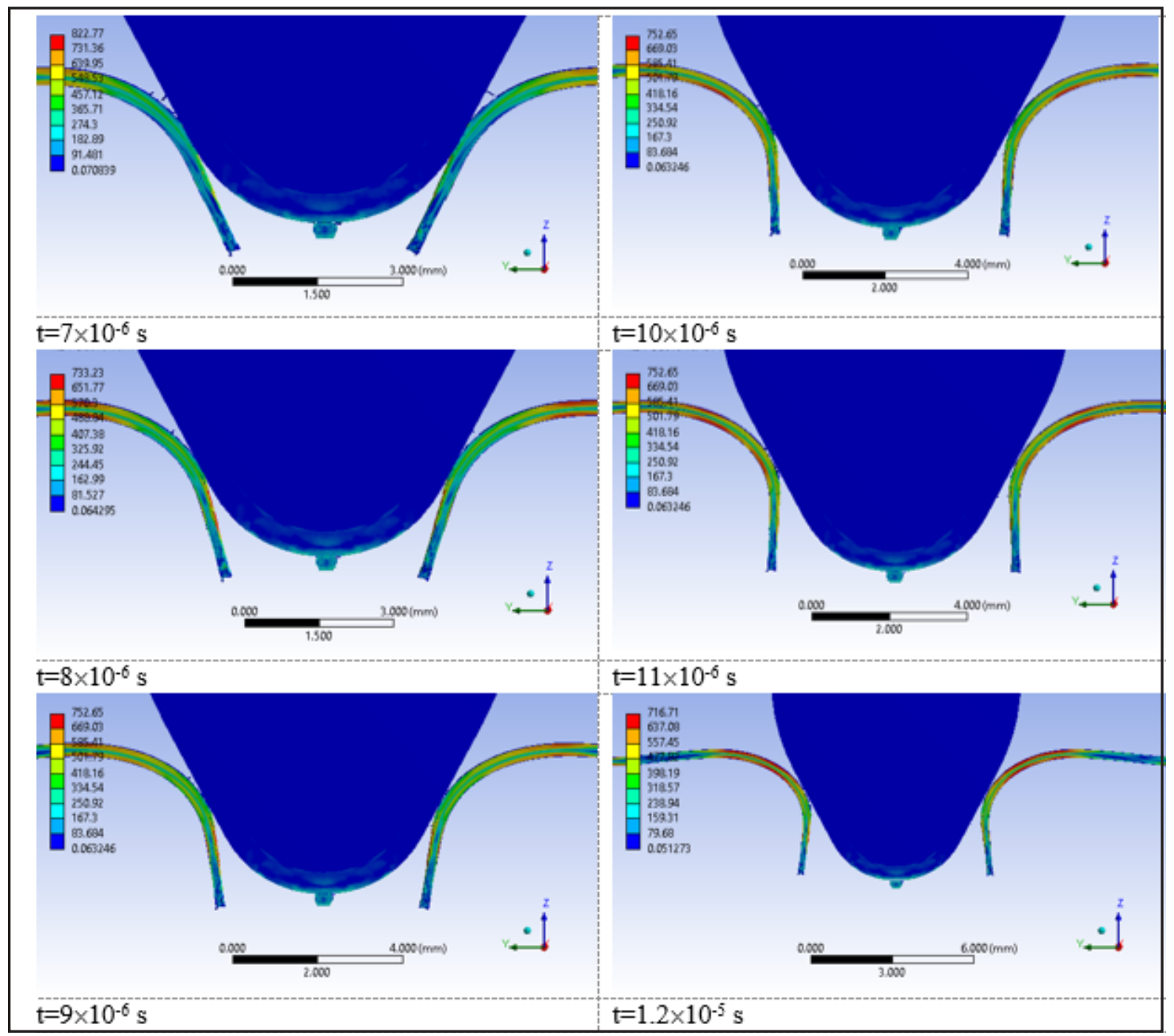

Fig. 6. Failure of the yarn at different moment after its rupture

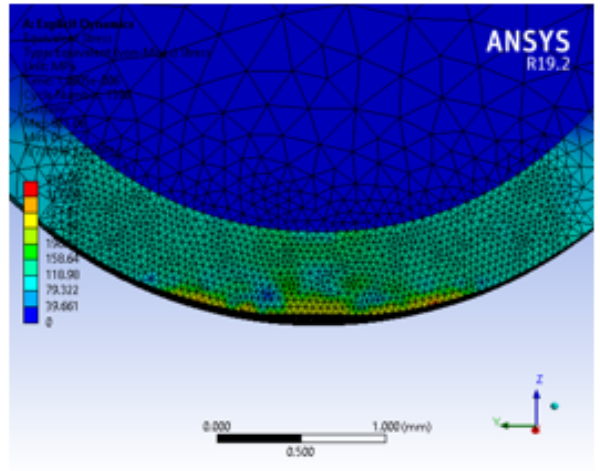

a) the top of the bullet, deformed by the impact

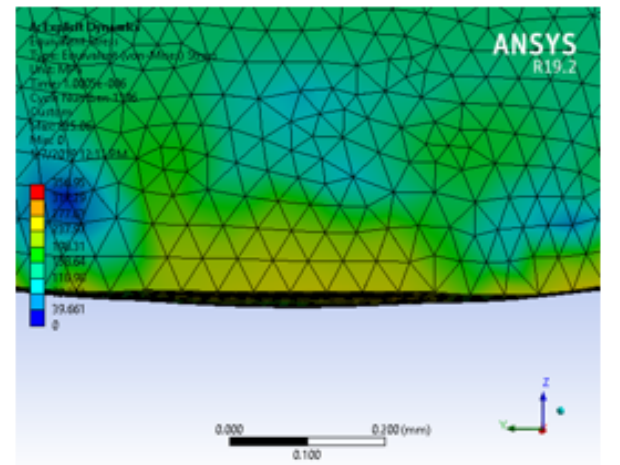

b) detail of the top of the bullet
Fig. 7 Detail of the yarn and the bullet in the contact zone, Yarn is attached on the deformed top of the bullet, at moment $\mathrm{t}=1 \cdot 10^{-5}$ 
Analyzing the yarn failure caused by a bullet and correlating with the evolution of maximum value of von Mises stress (fig. 8), the following stages in the failure process were identified.

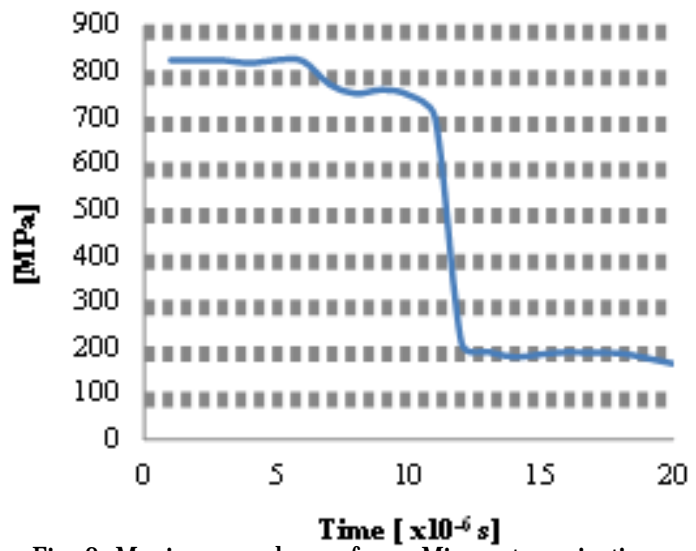

Fig. 8. Maximum values of von Mises stress in time

1. First, the yarn is pushed by the bullet, being in contact with the bullet and changing its linear shape into a curved one, following the bullet top shape (fig. 3a and detail in fig. $6)$. For this simulation the deformation and the displacement of the yarn without breakage is lasting for only $2 \times 10^{-6} \mathrm{~s}$.

2. As the bullet impingement is localized, the local elongation of the yarn is tacking place (in zones situated at approximately at $20 \ldots 30^{\circ}$ to weight center of the bullet axle). In figure $3 d$, there are two zones of reduction section, approximately symmetrical to the vertical axes of the bullet and being at a radius of $1 / 3 \ldots 1 / 2$ of the bullet radius to this axle. The yarn is not yet broken at the moment time $2 x$ $10^{-6} \mathrm{~s}$.

3. At moment time during the impact $3 \times 10^{-6} \mathrm{~s}$, the yarn rupture occurs in the thinner (strangled) zones, due to local elongation of the yarn, caused by the stretch of the yarn directly supporting the impact (Moment time $\left.4.5 \times 10^{-6} \mathrm{~s}\right)$. The breaking the yarn in the thinned zone (more pronounced asymmetric breaking in actual process, see fig. 11c and d)) and it is visible that the yarn elastic recoil starts next to the bullet. The friction between the yarn and the bullet is only on the conical surface of the bullet.

Zones with high stress remain in the yarn till $7 \times 10^{-6} \mathrm{~s}$, as one may see in figure 6 . Figure 7a shows how the bullet top was deformed by the impact with the yarn, with a detail in figure $7 \mathrm{~b}$.

4. The long broken fragments of the yarn are bent during the bullet passage in contact with them (the contact zones between the bullet and the yarn in polymeric matrix become smaller, justifying a neglectable influence of the thermal effect). The approximately central fragment of the yarn remains on the bullet top and it is probably that this is bearing a more significant thermal influence as the bullet would have higher temperature because a quantity of the kinetic and friction energy will be transform into heat (see the photos of the bullets, fig. 10). The polymeric matrix (in actual fabrics, it may be polyethylene [60]) plays the role of a sticky material, especially if the temperature rises.

It is interesting to mention that the analytical model presented by Langston [61] propose a similar failure process at macro scale, that is for a composite made of plies.

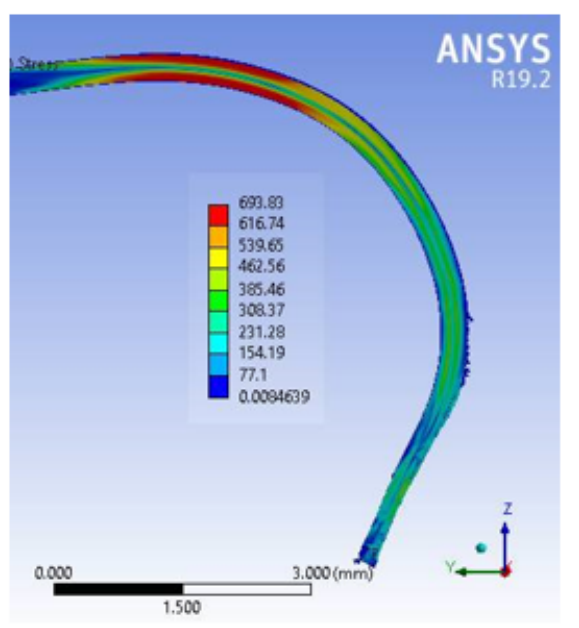

a) yarn and PE matrix

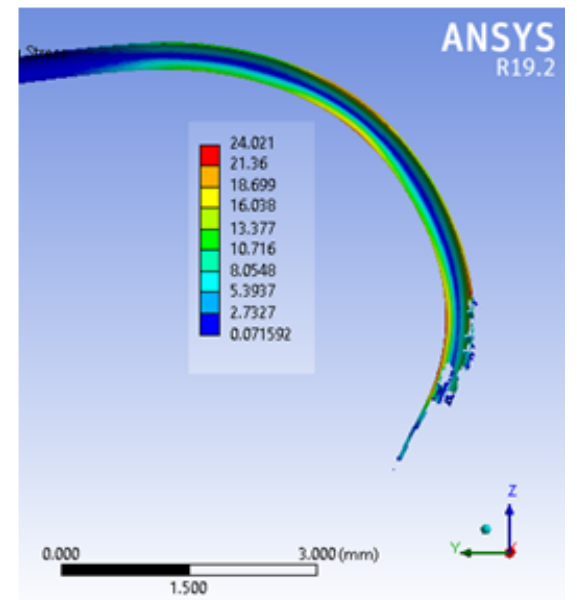

b) PE matrix

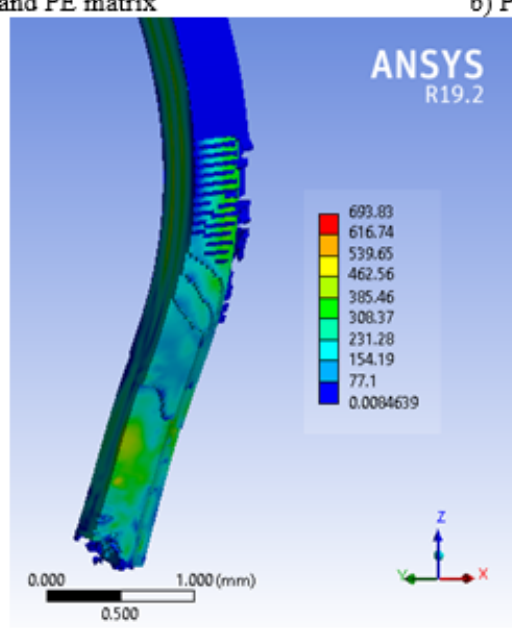

c) Detail of the broken end of the yarn
Fig. 9. Details of the broken end of the yarn with properties similar to aramid ones in a polymeric matrix $t=2 \times 10^{-5} \mathrm{~S}$ 
The effect of yarn wiping is more pronounced if the yarn is thinner. These stages as described by the authors have a time duration between $10^{-5} . .1 .5 \times 10^{-5} \mathrm{~s}$.

Figure 9 presents details of the left part of the yarn and matrix at $210^{-5} \mathrm{~s}$, pointing out that stress due to bending still has high values, and this stress distribution (fig. 9a) could explain the longitudinal split of the fibers (see SEM image in fig. 11c, fiber in the left corner). Also, the fragmentation of the matrix in the contact zone seems very plausible as broken fibers has small spots of PE on them, as one may see in figure $9 d$ and the matrix does not seem to be molten, thus, this is a proof of low thermal influence in this impact process.

In figure $7 \mathrm{~b}$, it is noticeable that the polymeric matrix was entirely detached from the yarn along $1.5 . .2 \mathrm{~mm}$; but after this zone, the polymeric matrix remains attached on the yarn, small fragments are detached on a length of $1 . . .4$ $\mathrm{mm}$. It may be considered that the polymeric material on the yarn is beneficial for maintaining the order among the yarns, these being obliged by this matrix to stay in line, that is to reduce the pull-out and lateral impingement of the yarns $[62,63]$. The yarn has a reduction in section (bottleneck) just after the broken section; in reality, this thinned zoned could be curled or twisted due to the smaller diameter of the fibers, to the influence of neighboring fibers, of the twisting of the bullet near them etc. In figure $7 b$, the yarn is made invisible, the fragmentation of the polymeric matrix and the detaching of fragments being more evident, this process of fragmenting and partial detaching of the matrix being a supplementary mechanism of energy dissipation.

The bullet is deforming, bearing the yarn action and a yarn fragment remains attached on the front of the bullet, as one maynotice studying the photos of the bullets arrested in the pack (fig. 10).

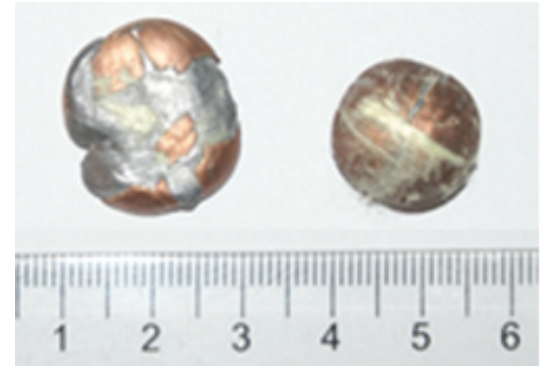

Fig. 10. Bullets from rigid panels (left - from panels made of fabrics LFT SB1, right from panels made of fabrics CT 709) (total arrest in the panels) [35]

The images from simulation were compared to photographs obtained on fibers and bullets, with the help of an electron scanning microscope. Qualitatively, this model of the yarn failure is presented in figures 3 and 4 , validated by photos of the bullets, especially on the bullet arrested in a rigid pack with layers of CT709 fabrics, bonded with a PVB resin [35]. When analyzing the bullet extracted from a pack made of LFT SB1, there are noticed yarn fragments, differences in shape and size of the fragments maybe exists because of the higher degree of the bullet deformation, allowing for the yarn fragments to slip away or to remain on the bullet. also, indentations of the yarn fragments could be seen (fig. 11d).

Figure 11 presents details of the broken fibers from the first layer of LFT SBplus: a) a fiber with locally stretched zones, one at the broken end and the other at $20 . . .30 \mathrm{~mm}$ distance, having $20 . . .25 \mu \mathrm{m}$ in length, b) a magnification of the stretch zone, the dimension of the yarn being 1...1.3 $\mu \mathrm{m}$, the initial cross dimension of the fiber being $9 . . .11 \mu \mathrm{m}$.

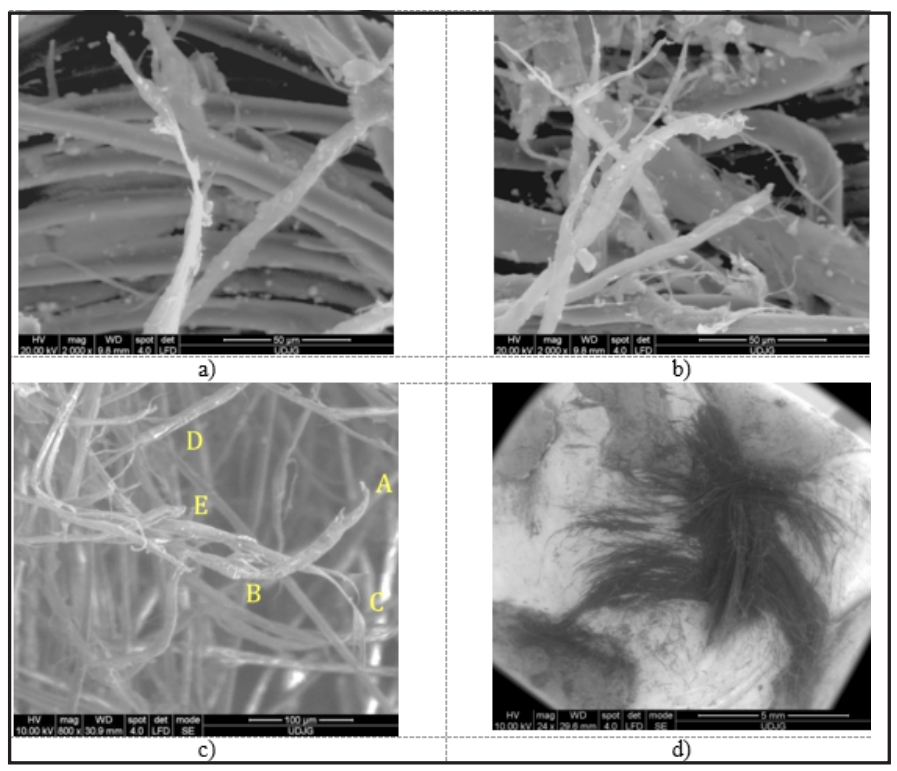

Fig. 11. Details of the fibre failure in the first layer of a stratified packmade of LFT SBplus

The actual process of fiber rupture include elongation till break but also other mechanisms of failure, like shear, microfibrilation of the fiber etc. (fig. $11 \mathrm{c}$ and d). Letters in figure 11c means: A - broken end of a fiber, with a bottleneck thinning, $B$ - thinning without brakage (it is possible that this piece of fiber $A B$ to have been on the bullet tip, $C$ brakage with fiber splitting, D - spliiting along the fiber without thinning and the brakage was ocurred with thinning an splitting the fiber (here, the broken fiber end has three thin wiskers, E - brakage with evident shearing, thinning coul be observed on the fiber. It is obvious that the broken fibers were bending in the plastic domain (thus, with high stress), taking into account the position of the fibers as curls. On images in figure $11 b$, there are visible small fragments from the polyethylene foils used to form the fabrics (for LFT SBplus there are 5 PE foils between the four sub-layers of unidirectional fibers arranged at different angles [0/90/45/-45].

\section{Conclusions}

This model of damaging the yarn in a polymeric matrix allows for establishing stages of the process characterising the ballistic impact between a bullet and a yarn, pointing out processes and phenomena that are difficult to be observed during the actual impact. The yarn shape from the presented model after the impact is similar to the fiber shape as obtained after an actual impact as it was observed with the help of SEM images on yarns made of aramid fibers.

Analyzing the yarn failure caused by a bullet, the FE model allows for identifying the stages in the failure process. First, the yarn is pushed by the bullet and the local elongation of the yarn is tacking place. The yarn rupture occurs in the strangled zones, caused bythe stretch of the yarn directly supporting the impact. The breaking of the yarn in the thinned zone (more pronounced asymmetric breaking) and it is visible that the yarn elastic recoil starts next the bullet. The friction between the yarn and the bullet was modeled with a constant friction coefficient. The bullet moves, contacting the yarn in different areas, this is, probably the cause of a small influence of the thermal effect for this range of impact velocity (till $400 \mathrm{~m} / \mathrm{s}$ ). In the actual multi-yarn impact, the other yarns in the first layers and the layers of yarns maintain the bullet and the first yarns in contact and this is why bunch of fibers (fragments 
of the failed yarns) are pressed against the bullet and remain on its.

The simulation results were qualitatively validated by SEM investigations of fiber failure under similar conditions (impact velocity, bullet mass and shape), as the model.

\section{References}

1. AL-BASTAKI, N.M.S., Applied Composite Materials, 5, 1998, pp. 223236

2. BARBERO, E.J ., DE, VIVO L., Intern. J. of Damage Mechanics, 10, 2008, pp. 73-93

3. GRUJ ICIC, M., ARAKERE, G., HE, T., BELL, W.C., CHEESEMAN, B.A, YEN, C.-F., SCOTT, B., Materials Science and Engineering A, 498, 2008, pp. 231-241

4. HIERMAIER, S., RIEDEL, W., CLEGG, R., HAYHURST, C., Advanced material models for hypervelocity impact simulations, Tech. Rep., ESA/ESTEC Contract no. 12400/97/NL/PA(SC), 1999

5. PIGGOTT, M.R., J. of Materials Science, 16, 1981, pp. 2837-2845

6. NASTASESCU, V., MARZAVAN, S., Mat. Plast., 54, no. 2, 2017, pp. 195202

7. JOHNSON, G.R., COOK, W.H., Proc. of the 7th Intern. Symposium on Ballistics, The Hague, 19-21 April 1983, pp. 541-547

8. J OHNSON, G.R., Intern. J . of Impact Engineering, 38, 2011, pp. 456472

9. MENIKOFF, R. Complete Mie-Gruneisen equation of state, Report, LA-UR-12-22592, https://permalink. lanl.gov/object/tr?what=info:lanlrepo/lareport/LA-UR-12-22592, 2012

10. SCHWER, L., Optional strain-rate forms for the Johnson Cook constitutive model and the role of the parameter Epsilon_01, Impact, 6. LS-DYNA Anwenderforum, Frankenthal, 2007

11. TERMONIA, Y., SMITH, P., A Theoretical Approach to the Calculation of the Maximum Tensile Strength of Polymer Fibers, 1988, pp. 321362, in High Modulus Polymers, A. E. Zachariades, R. S. Porter, eds., Marcel Dekker, New York

12. SMITH, J.C., MCCRAKIN, F.L., SCHNIEFER, H.F., Textile Research Journal, 28(4), 1958, pp. 288-302

13. KNOFF, W.F., J. of Materials Science, 22, 1987, pp. 1024-1030

14. TABIEI, A., IVANOV, I., Intern. J. of Non-Linear Mechanics, 39, pp. $175-188,2004$

15. TABIEI, A., NILAKANTAN, G., Applied Mechanics Reviews, 61, 2008, pp. 010801-010813

16. CORMOS, R., PETRESCU, H., HADAR, A., ADIR, G. M., GHEORGHIU, H., Mat. Plast., 54, no. 1, p. 180-185, 2017

17. LIM, J.S., LEE, B.H., LEE, C.B., HAN, I.-S., Engineering, 4, pp. $944-$ 949, 2012

18. WANG, Y., XIA, Y., J. of Materials Science Letters, 19, 2012, pp. 583586

19. WAGNER, D.H., SCHWARTZ, P., PHOENIX, S.L., J. of Materials Science 21(6), 1986, pp. 1868-1878

20. MISHNAEVSKY, L. JR., Computational Mesomechanics of Composites. Numerical analysis of the effect of microstructures of composites on their strength and damage resistance, John Wiley \&Suns Ltd, 2007, pp. 37

21. MISHNAEVSKY, L. JR., BRØNDSTED, P., Micromechanical Modeling of Strength and Damage of Fiber Reinforced Composites, 2007, Annual Report on EU FP6 Project UpWind integrated wind turbine design (WP 3.2)

22. BOTAN, M., DANILA, D., PIRVU, C., DELEANU, L., Mat. Plast., 52, no. 1,2015 , pp. 20-23

23. JIA, X., SUN, B., GU, B., Intern. J. of Damage Mechanics, 237(17), 2011, pp. 2012-2021

24. JIN, L., HU, H., SUN, B., GU, B., Composites: Part B, 2010, 41, pp. 337-353

25. NGUYEN, L.H., LASSIG, T.R., RYAN, S., RIEDEL, W., MOURITZA, A. P., ORIFICI A. C., The 13th Hypervelocity Impact Symposium, Procedia Engineering, 103, 2015, pp. 436-443

26. OTHMAN, A.R., HASSAN, M.H., Materials and Design, 44, 2013, pp. 407-413, Elsevier Ltd.
27. ROYLANCE, D., CHAMMAS, P., TING, J., CHI, H., SCOTT, B., Proc. of the National Meeting of the American Society of Mechanical Engineers (ASME) San Francisco, October 1995

28. SHIM, V.P.W, LIM, C.T., FOO, K.J., Intern. J. of Impact Engineering, 25, 2001, pp. 1-15

29. LIM, C.T., SHIM, V.P.W., N.G., Y.H., Intern. J . of Impact Engineering, 28(1), 2003, pp. 13-31

30. GOGINENI, S., Finite element analysis of ballistic penetration of plain weave Twaron $\mathrm{CT} 709 \circledR$ fabrics. A parametric study, Texas A\&M University, 2010

31. TERMONIA, Y., Textile Research J ournal, 748, 2004, pp. 723-729

32. *** Chapter 9 Material Models. ANSYS AUTODYN, February 27, Inventory \#002665, 2009

33. *** AutoDyne composite modeling, ANSYS Inc., Published in USA, 2012

34. PERONI, L., SCAPIN, M., FICHERA, C., MANES, A., GIGLIO, M., EPJ Web of Conferences 26, 2012, 01060

35. PIRVU, C., Contributions on Experimental and Numerical Study of Ballistic Protection Packs Made of Aramid fibers (in Romanian), PhD thesis, Dunarea de Jos University of Galati, 2015

36. TAN, P., LEE, B., TSANGALIS, C., J. of Sandwich Structures and Materials, 13(3), 2010, pp. 263-278

37. TAN, V.B. C., ZENG, X.S., SHIM, V.P.W., Intern. J. of Impact Engineering, 35, 2008, pp. 1303-1313

38. SOCKALINGAM, S., GILLESPIE, JR. J. W., KEEFE, M., Intern. J. of Solids and Structures, 67-68, 2015, pp. 297-310

39. SOCKALINGAM, S., GILLESPIE, JR. J. W., KEEFE, M., Intern. J. of Solids and Structures, 51, 2014, pp. 2504-2517

40. WADA, Y., ITANI A., NISHI, T., NAGAI, S., J. of Polymer Science. Polymers Physiscs. Part B, 1969.

41. SEGLETES S. B., An analysis on the stability of the Mie-Groneisen equation of state for describing the behavior of shock-loaded materials, Technical Report BRL-TR-3214, 1991, http://www.dtic.mil/ dtic/tr/fulltext/u2/a233827.pdf

42. PEIJ S, T., SMETS, E.A.M., GOVAERT, L. E., Applied Composite Materials, 1, pp. 35-54, Kluwer Academic Publishers, 1994

43. ALIL, L.C., ARRIGONI, M., DELEANU, L., ISTRATE, M., Mat. Plast., 55(3), pp. 364-317, 2018

44. LASSIG, T., NGUYEN, L., MAY, M., RIEDEL, W., HEISSERER, U., VAN DER WERFF, H., HIERMAIER S., Intern. J. of Impact Engineering, 75, pp. 110-122, 2015

45. OZBOLT, J., LACKOVIC, V., KROLO, J., Intern. J. of Fracture, 170(1), pp. 13-26, 2011

46. CHEN, F., ZHOU, L., TANG Y., ZHOU, X., An analytical modeling for high-velocity impacts on woven Kevlar composite laminates, JVE International Ltd., 2017, Kaunas, Lithuania, pp. 249-256

47. DRAGHICI, S., PETRESCU, H.A., HADAR, A., Mat. Plast., 55, no. 4, 2018, p. 712-717

48. GOPINATH, G., ZHENG, J. Q., BATRA, R. C., Composite Structures, 94, pp. 2690-2696, 2010

49. J ONES, N., Structural Impact, 2nd Ed., Cambridge University Press, 2012

50. KATZ, S., ZARETSKY, E., GROSSMAN, E., WAGNER, H. D., Composites Science and Technology, 69, pp. 1250-1255, 2009

51. REIS, P.N.B., FERREIRA, J.A. M., SANTOS, P., RICHARDSON, M.O.W., SANTOS, J.B., Composite Structures, 94, pp. 3520-3528, 2012

52. THAM, C.Y., TAN, V.B. C., LEEA H.P., Intern. J of Impact Engineering, 35, pp. 304-318, 2008.

53. *** Shock EOS Linear, https://www.sharcnet.ca/Software/Ansys/ 17.0/en-us/help/exd_ag/ds_ex_mat_shockeos.html

54. LUKYANOV, A.A., An Equation of State for Anisotropic Solids under Shock Loading, https://arxiv.org/pdf/0911.4717.pdf, 2009

55. NASTASESCU, V., STEFAN, A., LUPOIU, C., Analiza neliniarã prin metoda elementelor finite. Fundamente teoretice si aplicatii, Editura Academiei Tehnice Militare, Bucuresti, 2002

56. HUB, J., AAR, M.S., 8, no. 2, pp. 339-344, http://zmne.hu/aarms/ docs/Volume8/Issue2/pdf/14hub.pdf, 2009 
57. HUB, J., Some Aspects of Machine Gun Penetration of the Aluminium Sheet-Metal Plate using Ansys Autodyn, ANSYS konference 2010, February 6-8, http://www.ansys.stuba.sk/ANSYS2010/prednasky /Ansys\%20Mechanical/Hub_Some_aspects_of_machine_gun_bullet penetration_of the_aluminium_sheet-metal_plate_using_ansys_ autodyn.pdf, $20 \overline{10}$

58. GRUJICIC, M., BELL, W.C., GLOMSKI, P.S., PANDURANGAN, B., YEN, C.-F., CHEESEMAN, B.A., J of Materials Engineering and Performance, 20, 2011, pp. 1401-1413

59. NILAKANTAN, G., GILLESPIE, JR.J.W., Composite Structures, 94, 2012, pp. 3624-3634
60. NILAKANTAN, G., NUTT, S., Composite Structures, 116, 2014, pp. 661-669

61. *** Ballistics Teijin Aramid, Ballistics material handbook 38-1405/ 2012.

62. LANGSTON, T., Composite Structures 179, 2017, pp. 245-257 63. PIRVU, C., DELEANU, L., Ballistic testing of armor packages based on aramid fibers, in Charles Osheku (editor) Ballistics, IntechOpen, London, DOI: 10.5772/intechopen.78315, 2018

Manuscript received: 18.12 .2018 